\title{
Delayed tail loss during the invasion of human skin by schistosome cercariae
}

\author{
P. J. WhitFiELD ${ }^{1 *}$, A. BARTLETT ${ }^{1}$, N. KHAMMO ${ }^{2}$, A. P. R. BRAIN ${ }^{1}$, M. B. BROWN ${ }^{1}$, \\ C. MARRIOTT ${ }^{1}$ and R. CLOTHIER ${ }^{2}$ \\ ${ }^{1}$ School of Health and Life Sciences, King's College London, 150 Stamford Street, London SE1 9NN \\ ${ }^{2}$ University of Nottingham, School of Biomedical Sciences, Queens Medical Centre, Nottingham NG7 2UH
}

(Received 19 Fuly 2002; revised 27 September 2002; accepted 27 September 2002)

\begin{abstract}
S U M M A R Y
Schistosomiasis is initiated when cercarial larvae invade human skin. Contrary to long-held assumptions, most cercariae of Schistosoma mansoni do not shed their propulsive tails as they penetrate. Scanning electron microscopy studies and infection experiments with entire human skin and differentiated, stratum corneum-like, human keratinocyte cultures, have shown that most cercarial tails enter the skin along with their bodies. We propose that this behaviour is an adaptive trait linked with concomitant immunity.
\end{abstract}

Key words: Schistosoma mansoni, tail loss, cercariae, invasion, concomitant immunity.

\section{INTRODUCTION}

During scanning electron microscopy (SEM) investigations of the process by which cercariae of Schistosoma mansoni invade human skin and cultured human skin cells (Khammo et al. 2002), we have repeatedly obtained images which suggested that cercarial tails were not being shed as penetration took place. This would be contrary to long held assumptions that most schistosome cercariae lose their tails at the onset of penetration (Wilson, 1987; Sturrock, 1993; McKerrow \& Salter, 2002). The presumed loss of tails would ally schistosomes with the great majority of other digenean species that shed their tails as they infect hosts and/or form metacercarial cysts (Erasmus, 1972).

The SEM evidence suggested that the majority of tails might remain attached to heads as they penetrated human skin. We have carried out a range of descriptive and quantitative experiments to validate this conclusion and to assess the extent to which this phenomenon, which we term delayed tail loss (DTL), occurs in different infection conditions.

\section{MATERIALS AND METHODS}

\section{Parasites}

The life-cycle of Schistosoma mansoni was maintained in NMRI strain mice and Biomphalaria glabrata as previously described (Khammo et al. 2002). Tap water used with snails and cercariae was filtered to

* Corresponding author: School of Health and Life Sciences, King's College London, 150 Stamford Street, London SE1 9NN. Tel: +0207848 4646. E-mail: phil.whitfield@kcl.ac.uk remove heavy metals and chlorine (Carbon-resin filter, Prosep Filter Systems Ltd). Cercariae for experiments were obtained from infected snails by stimulation with bright light for $1 \mathrm{~h}$ at $26^{\circ} \mathrm{C}$. In each infection experiment the cercariae were separated from the snails and $5 \times 1 \mathrm{ml}$ samples of the uniform suspension were taken, fixed and stained with Lugol's iodine, and counted under low magnification. This gave the mean number of organisms/ml separately categorized as whole cercariae, detached heads and detached tails. Suspensions of cercariae for experiments were diluted with filtered water to the required concentration of not more than 200/ml.

\section{Keratinocyte cultures}

Cultures of human keratinocytes were differentiated for 14 days on Cellogen ${ }^{\mathrm{TM}}$ (ICN Biochemicals Inc) cross-linked collagen cell support membranes (Khammo et al. 2002).

\section{Experiments with whole human skin}

(i) Abdominal skin. In this and the experiments described below, S. mansoni cercariae of less than $2 \mathrm{~h}$ post-emergence age were used. Franz cells were used for experiments with human abdominal skin as previously described (Bartlett et al. 2000), which involved the use of skin that had been frozen for storage and thawed before use. Infection experiments were carried out with replicate $(n=5)$ samples of skin from a single donor (donor A1) and cercarial suspension volumes of $5 \mathrm{ml}$. Quantitative assessment of penetration (see below) was carried out at 5, 10 and 60 min post-exposure. 
To check that the freezing/thawing process did not affect subsequent skin penetration behaviour by cercariae, a control experiment was carried out with skin from another donor (donor A2). Half of this fresh skin sample was frozen at $-20{ }^{\circ} \mathrm{C}$ while the other half was stored overnight at $4{ }^{\circ} \mathrm{C}$. On the following day both samples were brought to room temperature and then used in a quantitative assessment of penetration at $60 \mathrm{~min}$ post-exposure as described above (fresh skin, $n=9$; frozen/thawed skin, $n=7$ ).

(ii) Human foreskin. Cercariae were applied in plastic rings sealed with soft paraffin wax to washed whole, non-frozen, human foreskins obtained from 5 different donors (B-F). One $\mathrm{ml}$ aliquots of cercarial suspension, of known density, were used to infect the target preparations, for periods of 5, 10, 20, 40 or $60 \mathrm{~min}$, with replication levels between $n=5$ and $n=14$.

\section{Experiment with differentiated human keratinocytes}

Keratinocyte cultures on Cellogen ${ }^{\mathrm{TM}}$ (ICN Biochemicals Inc) membranes, in 24-well microtitre plates, were exposed to $0.5 \mathrm{ml}$ of cercarial suspensions of known density. Penetration assessments were made at 5 and 10 min post-exposure. Replication level was $n=5$ at each time-point.

SEM studies were made of representative cultures of keratinocytes after removal of unattached cercariae at $10 \mathrm{~min}$. The cultures were fixed in $2 \%$ glutaraldehyde in $0 \cdot 1 \mathrm{M}$ cacodylate buffer $(\mathrm{pH} 7 \cdot 4)$ for $3 \mathrm{~h}$ at $4{ }^{\circ} \mathrm{C}$ then post-fixed in $1 \%$ osmium tetroxide, in the same buffer, for $1 \mathrm{~h}$ at $4{ }^{\circ} \mathrm{C}$. They were critical-point dried, sputter-coated with gold/palladium and examined in a Philips SEM-501B operated at $15 \mathrm{kV}$.

\section{Quantitative assessment of infection}

Cercarial suspensions were removed after the timeintervals stated and pooled with an equal volume of filtered water used to wash the target surface. Postinfection counts were made of whole cercariae (W), cercarial heads $(\mathrm{H})$, and tails $(\mathrm{T})$ after fixation and staining with Lugol's iodine. If pre-infection counts were $\mathrm{W}_{1}, \mathrm{H}_{1}, \mathrm{~T}_{1}$, and post-infection values $\mathrm{W}_{2}, \mathrm{H}_{2}, \mathrm{~T}_{2}$, percentage cercarial attachment was estimated by $100-\left(\left(\mathrm{W}_{2}+\mathrm{H}_{2}\right) /\left(\mathrm{W}_{1}+\mathrm{H}_{1}\right) \times 100\right)$ and percentage DTL by $\left(\left(\mathrm{W}_{1}+\mathrm{T}_{1}\right)-\left(\mathrm{W}_{2}+\mathrm{T}_{2}\right) /\right.$ $\left.\left(\mathrm{W}_{1}+\mathrm{H}_{1}\right)-\left(\mathrm{W}_{2}+\mathrm{H}_{2}\right)\right) \times 100$. The latter quantitative definition compares the number of retrieved tails with that expected if all penetrating cercariae had shed their tails into the surrounding medium. By definition, $100 \%$ DTL would represent no newly separated tails in the surrounding medium and $0 \%$ DTL a situation in which all penetrating cercariae released their tails into the medium. Standard deviations were calculated using arcsine transformed percentage values.
RESULTS

\section{SEM studies}

Fig. 1A provides an example of the category of SEM image which demonstrates that cercarial tails are taken into the stratum corneum-like outer layers of a differentiated, human keratinocyte culture. In this instance only the furcate posterior tip of the tail and the posterior extremity of the tail stem are visible superficial to the outermost cell layer of the culture. The cercarial body and the remainder of the tail stem are in the tunnel formed by the penetrating body. The tunnel diameter approximates very closely to the diameter of the tail stem. Other images (not shown) have indicated intermediate stages between the initiation of head penetration and the late phase illustrated in Fig. 1A.

Fig. 1B illustrates an entire cercaria beginning to penetrate the cross-linked collagen (Cellogen ${ }^{\mathrm{TM}}$ ) at the edge of a differentiated keratinocyte culture. It shows the array of backward-pointing tegumental spines on the tail stem and furcae.

\section{Quantitative infection experiments}

Table 1 combines the results of quantitative infection experiments using abdominal skin with Franz cells, foreskin samples with plastic rings and differentiated human keratinocytes on Cellogen ${ }^{\mathrm{TM}}$ membranes. The table summarizes results in respect of percentage attachment of cercariae and percentage DTL at different time-intervals after exposure of the targets to cercariae.

The results in Table 1 show that only a very small fraction of the penetrating cercariae shed their tails into the external medium, with mean values of about $27 \%, 16 \%$ and $9 \%$ for infections of abdominal skin, foreskin and differentiated keratinocytes respectively. In the experiments with human skin, the considerable deficit of separated tails persisted until $60 \mathrm{~min}$ after the initiation of infection. Previous results have shown that maximal attachment/ penetration of skin occurs by $5 \mathrm{~min}$ (Bartlett et al. 2000). We assume therefore, that the unaccountedfor tails had entered the epidermis.

The control experiment demonstrated that freezing and thawing did not alter either the percentage attachment of cercariae or the degree of tail retention. Fresh and frozen/thawed samples from the same donor elicited very similar attachment $(86.9 \%$ and $86 \cdot 2 \%$ respectively) and delayed tail loss $(68.9 \%$ and $69 \cdot 1 \%$ ), after 60 min exposure.

\section{DISCUSSION}

About 50 years ago histological studies on the penetration of mouse skin by $S$. mansoni cercariae suggested that some cercarial tails entered the epidermis still attached to their heads (Gordon \& 

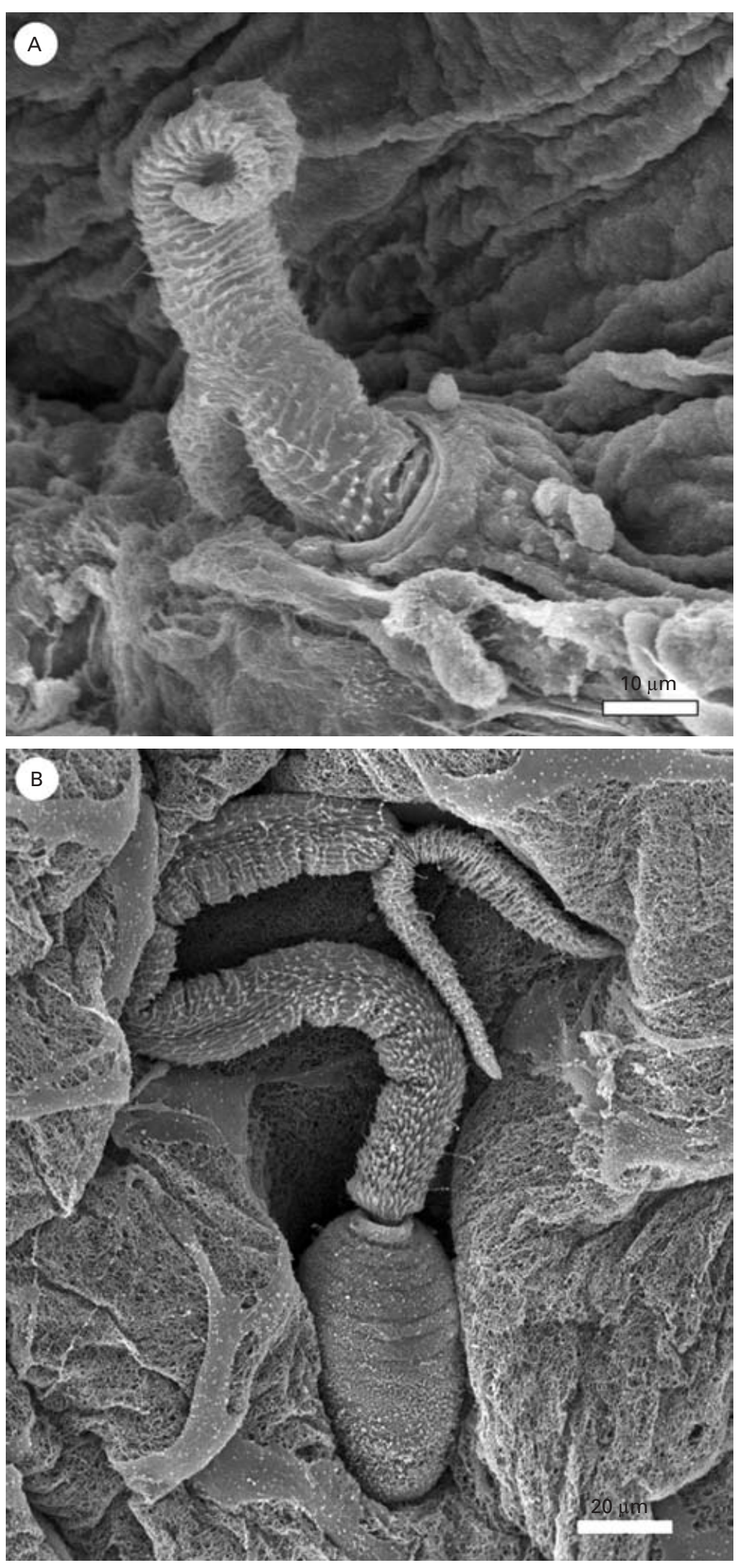

Fig. 1. (A) SEM of a cercaria of Schistosoma mansoni penetrating differentiated keratinocytes in culture. Only the posterior tip of the tail is visible. The cercarial body and the bulk of the tail are in the tunnel formed by the penetrating body. (B) SEM of entire cercaria beginning to penetrate cross-linked collagen at the edge of a differentiated keratinocyte culture. 
Table 1. Percentage attachment and percentage delayed tail loss (DTL) for infections of human skin and cultured human keratinocytes with cercariae of Schistosoma mansoni

\begin{tabular}{|c|c|c|c|c|c|c|c|c|c|c|c|c|c|c|c|c|}
\hline \multirow[b]{2}{*}{ Target } & \multirow[b]{2}{*}{$\begin{array}{l}\text { Support } \\
\text { system }\end{array}$} & \multicolumn{3}{|c|}{$5 \mathrm{Min}$} & \multicolumn{3}{|c|}{10 Min } & \multicolumn{3}{|c|}{$20 \mathrm{Min}$} & \multicolumn{3}{|c|}{$40 \mathrm{Min}$} & \multicolumn{3}{|c|}{$60 \mathrm{Min}$} \\
\hline & & $N$ & $\begin{array}{l}\% \text { Attached } \\
\text { (s.D.) }\end{array}$ & $\begin{array}{l}\% \text { DTL } \\
\text { (s.D.) }\end{array}$ & $N$ & $\begin{array}{l}\text { \% Attached } \\
\text { (s.D.) }\end{array}$ & $\begin{array}{l}\% \text { DTL } \\
\text { (s.D.) }\end{array}$ & $N$ & $\begin{array}{l}\% \text { Attached } \\
\text { (s.D.) }\end{array}$ & $\begin{array}{l}\% \text { DTL } \\
\text { (s.D.) }\end{array}$ & $N$ & $\begin{array}{l}\% \text { Attached } \\
\text { (s.D.) }\end{array}$ & $\begin{array}{l}\% \text { DTL } \\
\text { (s.D.) }\end{array}$ & $N$ & $\begin{array}{l}\% \text { Attached } \\
\text { (s.D.) }\end{array}$ & $\begin{array}{l}\% \text { DTL } \\
\text { (s.D.) }\end{array}$ \\
\hline $\begin{array}{l}\text { Whole human skin } \\
\text { Abdominal } \\
\text { Donor A1 } \\
\text { (Frozen/thawed) }\end{array}$ & $\begin{array}{c}\text { Franz } \\
\text { cells }\end{array}$ & 5 & $\begin{array}{l}95 \cdot 8 \\
(0 \cdot 9)\end{array}$ & $\begin{array}{l}77 \cdot 9 \\
(2 \cdot 3)\end{array}$ & 5 & $\begin{array}{l}96 \cdot 6 \\
(1 \cdot 3)\end{array}$ & $\begin{array}{l}82 \cdot 5 \\
(4 \cdot 1)\end{array}$ & & N.D. & N.D. & & N.D. & N.D. & 5 & $\begin{array}{l}96 \cdot 5 \\
(2 \cdot 1)\end{array}$ & $\begin{array}{l}69 \cdot 0 \\
(8 \cdot 13)\end{array}$ \\
\hline $\begin{array}{l}\text { Whole human skin } \\
\text { Abdominal } \\
\text { Donor A2 (Fresh) }\end{array}$ & $\begin{array}{c}\text { Franz } \\
\text { cells }\end{array}$ & & N.D.* & N.D. & & N.D. & N.D. & & N.D. & N.D. & & N.D. & N.D. & 9 & $\begin{array}{l}86 \cdot 9 \\
(4 \cdot 1)\end{array}$ & $\begin{array}{c}68 \cdot 9 \\
(10 \cdot 4)\end{array}$ \\
\hline $\begin{array}{l}\text { Whole human skin } \\
\text { Abdominal } \\
\text { Donor A2 } \\
\text { (Frozen/thawed) }\end{array}$ & $\begin{array}{c}\text { Franz } \\
\text { cells }\end{array}$ & & N.D. & N.D. & & N.D. & N.D. & & N.D. & N.D. & & N.D. & N.D. & 7 & $\begin{array}{l}86 \cdot 2 \\
(2 \cdot 4)\end{array}$ & $\begin{array}{l}69 \cdot 1 \\
(7 \cdot 0)\end{array}$ \\
\hline $\begin{array}{l}\text { Whole human skin } \\
\text { Foreskin } \\
\text { Donors B,C,D,E,F } \\
\text { (Fresh) }\end{array}$ & $\begin{array}{c}\text { Plastic } \\
\text { rings }\end{array}$ & 14 & $\begin{array}{l}70 \cdot 3 \\
(7 \cdot 0)\end{array}$ & $\begin{array}{l}87 \cdot 8 \\
(8 \cdot 72)\end{array}$ & 10 & $\begin{array}{l}95 \cdot 3 \\
(2 \cdot 3)\end{array}$ & $\begin{array}{l}88 \cdot 3 \\
(5 \cdot 4)\end{array}$ & 5 & $\begin{array}{l}84 \cdot 8 \\
(5 \cdot 1)\end{array}$ & $\begin{array}{l}87 \cdot 0 \\
(3 \cdot 81)\end{array}$ & 5 & $\begin{array}{c}74 \cdot 7 \\
(10 \cdot 0)\end{array}$ & $\begin{array}{c}85 \cdot 1 \\
(17 \cdot 9)\end{array}$ & 14 & $\begin{array}{l}67 \cdot 9 \\
(6 \cdot 9)\end{array}$ & $\begin{array}{c}71 \cdot 4 \\
(17 \cdot 4)\end{array}$ \\
\hline $\begin{array}{l}14 \text { day differentiated } \\
\text { human keratinocytes }\end{array}$ & $\begin{array}{l}0 \cdot 5 \mathrm{ml} \\
\text { Cellogen }^{\mathrm{TM}} \\
\text { membrane }^{-}\end{array}$ & 5 & $\begin{array}{l}92 \cdot 4 \\
(6 \cdot 0)\end{array}$ & $\begin{array}{l}91 \cdot 5 \\
(5 \cdot 8)\end{array}$ & 5 & $\begin{array}{l}85 \cdot 5 \\
(3 \cdot 3)\end{array}$ & $\begin{array}{l}89 \cdot 9 \\
(2 \cdot 8)\end{array}$ & & N.D. & N.D. & & N.D. & N.D. & & N.D. & N.D. \\
\hline
\end{tabular}

* N.D., Not done. 
Griffiths, 1951; Griffiths, 1953). The fact that these investigations involved implausibly high cercarial densities led to the general presumption that this finding represented an artefact of the non-physiological experimental conditions. This has helped generate the modern consensus (Wilson, 1987; Sturrock, 1993; McKerrow \& Salter, 2002) that the cercariae shed their tails at the onset of penetration. Stirewalt (1959), however, utilized unexceptional cercarial densities and was able to demonstrate tunnels enclosing tails in mouse skin biopsied immediately after 3 min of contact with cercariae. In parallel with that finding, the novel results of the present study suggest that penetration of tails is a genuine component of schistosome invasion of human skin.

The retention of tails by penetrating cercariae is particularly surprising as schistosome tail loss is easily induced in vitro by mechanical stimuli (Brink, McLaren \& Smithers, 1977) and by stimulation with molecules such as linoleate (Hara et al. 1993). Given the apparently facile induction of tail loss, our finding that up to $88 \%$ of penetrating cercariae can retain their tails while invading human skin and the fact that almost all other caudate cercariae shed their tails during host invasion (Erasmus, 1972), we conclude that the retention of tails in vivo during penetration of skin is a specifically adaptive behavioural trait. This finding also suggests a functional rationale for the presence of the unusual backward-pointing, tegumental spines that cover the tails of human schistosome cercariae. Such spines will presumably facilitate inward movement of the tails into the penetration tunnel and prevent retrograde movement.

Freshwater-adapted schistosome cercariae that emerge from snail hosts undergo profound changes when they penetrate skin to initiate infections. They transform into vertebrate-adapted schistosomula and in the process shed the antigenic surface of the cercarial tegument. They also acquire a heptalaminate tegumental plasma membrane which adsorbs a range of masking host proteins, including erythrocyte antigens, immunoglobulins, MHC class I and $\beta(2)$ microglobulin. This masking is thought to be a means of avoiding host immune damage to adult worms (Loukas et al. 2001), one arm of concomitant immunity $(\mathrm{CI})$ in which effective immune responses exist against invading larvae alongside persistent adult worm infection. Although, in mice, the immunity associated with a long-term schistosome infection is likely to be an artefact of pathology (Wilson, 1990), there is still considerable interest in the possibility that $\mathrm{CI}$ is a component of the complex immunological interactions between humans and their schistosome parasites.

It is in this context that we propose that schistosome cercarial DTL is a specific adaptation that carries a mixture of larval antigens into the skin of the human host to enhance the effectiveness of the antilarval arm of CI. The antigen mixture will include surface and internal antigens of the tail. Among the internal antigens will be paramyosin, a structural protein of tail musculature (Gobert, 1998). This source of paramyosin antigen might help explain the common occurrence of anti-paramyosin antibodies in the human Ig response to schistosome infection which has led to paramyosin being considered as a candidate anti-schistosome vaccine (Gobert, 1998). Even if the tails are taken only into the epidermal zone of the skin, tail antigens will be accessible to the immune system as epidermal Langerhans cells (immature dendritic cells) can act as antigen presenting cells and stimulate $\mathrm{T}$ cells in skin-draining lymph nodes (Sato \& Kamiya, 1995).

It has recently been suggested that it is possible to examine the causes and implications of CI from an evolutionary biological perspective (Brown \& Grenfell, 2001). One possibility that emerged from this analysis is that it could be advantageous for adult schistosomes (and presumably early-invading cercariae destined to become adult) to manipulate the immune responsiveness of their host to prevent future larval infections that could compete for parasite mates or preferred microhabitats within the host. DTL represents a newly recognized and easily monitored aspect of potential immune manipulation by parasites. It will be intriguing to assess its variability in contexts that could shed light on the existence or importance of such manipulation. One such circumstance that has already been identified (Brown \& Grenfell, 2001) is the possibility that there could be parasite sex-specific differences in the induction of immune responses. Our experimental system will enable this hypothesis to be tested in relation to DTL.

We thank the Sir Halley Stewart Trust for continuing support of our schistosome-related work and the industrial supporters of the FRAME Research Programme. We are also grateful for helpful discussions with Dr V. R. Southgate, Dr H. Davies, Dr B. Grenfell, Dr S. Brown and Ms Rebecca Ingram and for the suggestion from an anonymous referee that the 'fresh' versus 'frozen/thawed' skin control would aid the interpretation of the results.

\section{REFERENCES}

BARTLETT, A., BROWN, M., MARRIOTT, C. \& WHITFIELD, P. J. (2000). The infection of human skin by schistosome cercariae: studies using Franz cells. Parasitology 121, 49-54.

BRINK, L. H., McLAREN, D. J. \& SMithers, s. R. (1977). Schistosoma mansoni: a comparative study of artificially transformed schistosomula and schistosomula recovered after cercarial penetration of isolated skin. Parasitology 74, 73-86.

BROWN, S. P. \& GRENFELL, B. T. (2001). An unlikely partnership: parasites, concomitant immunity and host defence. Proceedings of the Royal Society of London, B 268, 2543-2549.

ERAsmus, D. (1972). The Biology of Trematodes. Edward Arnold, London. 
GOBERT, G. N. (1998). The role of microscopy in the investigation of paramyosin as a vaccine candidate against Schistosoma japonicum. Parasitology Today 14, $115-118$.

GORDON, R. M. \& GRIFFITHS, R. B. (1951). Observations on the means by which the cercariae of Schistosoma mansoni penetrate mammalian skin, together with an account of certain morphological changes observed in the newly penetrated larvae. Annals of Tropical Medicine and Parasitology 45, 227-243.

GRIFFITHS, R. B. (1953). Further observations on the penetration of mammalian skin by the cercariae of Schistosoma mansoni, with special reference to the effects of mass invasion. Annals of Tropical Medicine and Parasitology 47, 86-94.

hara, I., HaRa, S., FUSCO, A. C., SALAFsky, B. \& SHibuYa, T. (1993). Role of calcium ion in Schistosoma mansoni cercarial tail loss induced by unsaturated fatty acids. Fournal of Parasitology 79, 504-509.

KHAMmo, N., BARTLETT, A., ClOTHIER, R. H. \& WhitfiEld, P. J. (2002). The attachment of Schistosoma mansoni cercariae to human skin cells. Parasitology 124, 25-30.

LOUKAS, A., JONES, M. K., KING, L. T., BRINDLEY, P. J. \& McMANUS, D. P. (2001). Receptor for Fc on the surfaces of schistosomes. Infection and Immunity $\mathbf{6 9}$, 3646-3651.

McKerrow, J. H. \& SALTER, J. (2002). Invasion of skin by Schistosoma cercariae. Trends in Parasitology 18, 193-195.

SATO, H. \& KAMIYA, H. (1995). Role of epidermal Langerhans cells in the induction of protective immunity to Schistosoma mansoni in guinea-pigs. Immunology 84, 233-240.

STIREWALT, M. A. (1959). Chronological analysis, pattern and rate of migration, of cercariae of Schistosoma mansoni in body, ear and tail skin of mice. Annals of Tropical Medicine and Parasitology 53, 400-413.

STURROCK, R. F. (1993). The parasites and their life-cycles. In Human Schistosomiasis (ed. Jordan, P., Webbe, G. \& Sturrock, R. F.), pp. 1-32. CAB International, Wallingford.

WILSON, R. A. (1987). Cercariae to liver worms: development and migration in the mammalian host. In The Biology of Schistosomes from Genes to Latrines (ed. Rollinson, D. \& Simpson, A. J. G.), pp. 117-146. Academic Press, London, UK.

WILson, R. A. (1990). Leaky livers, portal shunting and immunity to schistosomes. Parasitology Today $\mathbf{6}$, 354-358. 